\title{
Is midsole thickness a key parameter for the running pattern?
}

\author{
Nicolas Chambon ${ }^{\mathrm{a}, \mathrm{b}, *}$, Nicolas Delattre ${ }^{\mathrm{b}}$, Nils Guéguen ${ }^{\mathrm{b}}$, Eric Berton ${ }^{\mathrm{a}}$, Guillaume Rao ${ }^{\mathrm{a}}$ \\ a Aix-Marseille University, CNRS, ISM UMR 7287, 163 Avenue de Luminy, 13288 Marseille Cedex 09, France \\ ${ }^{\mathrm{b}}$ Oxylane Research, Decathlon Campus, 4 Boulevard de Mons, 59665 Villeneuve d'Ascq, France
}

\section{A R T I C L E IN F O}

\section{Article history:}

Received 30 August 2013

Received in revised form 11 February 2014

Accepted 12 February 2014

\section{Keywords:}

Barefoot

Foot-strike

Minimalist shoe

Running

\begin{abstract}
A B S T R A C T
Many studies have highlighted differences in foot strike pattern comparing habitually shod runners who ran barefoot and with running shoes. Barefoot running results in a flatter foot landing and in a decreased vertical ground reaction force compared to shod running. The aim of this study was to investigate one possible parameter influencing running pattern: the midsole thickness. Fifteen participants ran overground at $3.3 \mathrm{~m} \mathrm{~s}^{-1}$ barefoot and with five shoes of different midsole thickness $(0 \mathrm{~mm}, 2 \mathrm{~mm}, 4 \mathrm{~mm}$, $8 \mathrm{~mm}, 16 \mathrm{~mm}$ ) with no difference of height between rearfoot and forefoot. Impact magnitude was evaluated using transient peak of vertical ground reaction force, loading rate, tibial acceleration peak and rate. Hip, knee and ankle flexion angles were computed at touch-down and during stance phase (range of motion and maximum values). External net joint moments and stiffness for hip, knee and ankle joints were also observed as well as global leg stiffness. No significant effect of midsole thickness was observed on ground reaction force and tibial acceleration. However, the contact time increased with midsole thickness. Barefoot running compared to shod running induced ankle in plantar flexion at touch-down, higher ankle dorsiflexion and lower knee flexion during stance phase. These adjustments are suspected to explain the absence of difference on ground reaction force and tibial acceleration. This study showed that the presence of very thin footwear upper and sole was sufficient to significantly influence the running pattern.
\end{abstract}

(c) 2014 Elsevier B.V. All rights reserved.

\section{Introduction}

For over forty years, athletic footwear companies developed technical concepts aiming at preventing different injuries. Previous studies reported that $30 \%$ of runners suffer of an injury during a 13 weeks training period [1] and that most common running injuries were patella femoral pain syndrome, illiotibial band friction syndrome, Achilles tendinitis, shin splints and plantar fasciitis [2]. Knee injuries represent approximately $25 \%$ of injuries observed, muscles end tendons are the most affected tissues [3]. Among the most important factors causing running injuries are the magnitude and the repetition of impacts. In order to palliate this problem modern running shoes are composed of an important midsole thickness often made of viscoelastic materials located under the

\footnotetext{
* Corresponding author at: Aix-Marseille University, CNRS, ISM UMR 7287, 163 Avenue de Luminy, 13288 Marseille Cedex 09, France. Tel.: +33 07629432 29; fax: +330320337501.

E-mail addresses: nicolas.chambon@oxylane.com,nico.chambon@gmail.com (N. Chambon).
}

heel [4]. In addition midsoles often integrate others materials such as PU foam, gel inserts or air cushion.

However, it seems that the use of a modern shoe incorporating these concepts has altered the barefoot running pattern observed in people who never ran with "modern" shoes [5]. While $80-90 \%$ of recreational runners impact the ground with the heel [6,7], various reasons suggest that heel-toe running is not the natural running pattern. Indeed the study of Lieberman et al. [5] showed that different populations such as the Kenyans from Rift Valley Province who usually run barefoot do not adopt the same foot strike pattern as "modern" society runners. Indeed habitually barefoot runners often land with the forefoot (forefoot strikers) or with a flat foot (midfoot strikers) [5]. Moreover the transient peak of the vertical ground reaction force (vGRF) usually observed during a heel-toe running stride tends to disappear during a forefoot strike. Transient peak and the associated loading rate are suspected to represent the harmful effects of repetitive impact during running $[8,9]$. This suggests that running barefoot or in minimalist shoes may have real benefits over shod running when considering impact magnitude.

For habitually shod runners, many changes concerning biomechanical running pattern have been observed when 
comparing barefoot and shod running. Previous studies have shown during barefoot running an increase of stride frequency $[10,11]$ and leg stiffness [12], lower knee flexion range of motion (FRoM) [13], decreased impact forces [10,14] and joint torques [15]. Moreover Bishop et al. [16] and Hamill et al. [14] observed ankle in dorsiflexion during shod running versus plantarflexion during barefoot running.

Although differences observed between barefoot and shod running for habitually shod runners seem to be less obvious than differences observed between habitually shod and habitually barefoot runners, it appears that significant adjustments exist between shod and barefoot running. Three main factors differentiate barefoot from shod running as a shoe is usually built with a thick and deformable sole, a difference of height between heel and forefoot (heel to toe drop), and an upper around the foot.

Midsole thickness is an important parameter concerning the plantar sensations and maybe a crucial parameter in the modification of foot strike pattern between shod and barefoot running. The study of Robbins and Gouw [17] suggested that modern shoes with thick and compliant midsoles attenuate plantar sensations at touchdown inducing the suppression of protective reflexes. Thus, the aim of the present study was to quantify the effect of midsole thickness on biomechanical responses during running for habitually shod runners.

It was hypothesized that a lower thickness would cause the foot strike pattern to be closer to the foot strike pattern observed in a barefoot condition, with a flatter foot at touch-down, therefore inducing lower impacts and lower net joint torques.

\section{Materials and methods}

\subsection{Participants}

Fifteen healthy male runners (age: $23.9 \pm 3.2$ years, height: $177 \pm 3 \mathrm{~cm}$, body mass: $73.0 \pm 8 \mathrm{~kg}$, EU shoe size: 43 ) volunteered for participation in the experimentation. Runners were university students of Aix-Marseille University (Marseille, France). All of them regularly practiced physical activities and had no previous histories of neurological disorders or physical injuries in the year before the experiment (statement of each participant). Fourteen participants were rearfoot strikers and one was midfoot striker (validated using high frequency video during a treadmill trial at $3.3 \mathrm{~m} \mathrm{~s}^{-1}$ ). All participants provided written informed consent prior to inclusion in this study, which was approved by the Local Ethical Committee.

\subsection{Conditions}

Five shod conditions and a barefoot condition (BARE) were tested in randomized order. All shoes have identical lightweight upper, no heel counter, outsole thickness ( $3 \mathrm{~mm}$ of rubber) and midsole hardness (60 Asker C). Shoe conditions only differed in midsole thicknesses: no midsole $(0 \mathrm{~mm}), 2 \mathrm{~mm}, 4 \mathrm{~mm}, 8 \mathrm{~mm}$ and $16 \mathrm{~mm}$. For each condition, the midsole had the same thickness under forefoot and rearfoot parts (i.e., $0 \mathrm{~mm}$ heel to toe drop). This choice was motivated, first, by the fact that running barefoot is obviously a $0 \mathrm{~mm}$ heel to toe drop condition, and, second, because it is the only possibility to test for the true influence of the thickness factor without having two intricate experimental conditions (i.e., midsole thickness and heel to toe drop).

In the next parts, "footwear conditions" will refer to all the experimental conditions (six in total), and "shod conditions" will refer to the five shoe conditions with the barefoot condition excluded.

\subsection{Experimental task}

For each condition, the position of the participant's markers was recorded during a static pose in the standard anatomical position. Then, for each condition, the subjects were asked to run on a stiff treadmill (Tecmachine ${ }^{\circledR}$ Médical Developpement S1200) at $3.3 \mathrm{~m} \mathrm{~s}^{-1}$ during $3 \mathrm{~min}$ for familiarisation. No measurements were made during the treadmill task. Then, participants had to run along a $15 \mathrm{~m}$ runway in which a force platform was located $10 \mathrm{~m}$ after the start of the run. Participant had to perform five valid running trials at $3.3 \mathrm{~m} \mathrm{~s}^{-1}$. Running speed was controlled by photocells apart from the force platform. All the trials were performed within $\pm 5 \%$ of the prescribed speed.

\subsection{Biomechanical measurements}

Eight cameras of an optoelectronic motion capture system (Vicon ${ }^{\circledR}$ T40 and T20) tracked forty reflective markers. Marker set used was based on principles described in Kadaba et al. [18] and used in Hamner et al. [19]. These markers were used to observe the kinematics of the hip, knee, and ankle joints as well as foot/ground angle during the task. GRF was measured by a force platform (Kistler ${ }^{\circledR}$ 9281 CA). Tibial acceleration along the tibia longitudinal axis was measured by a tri-dimensional accelerometer (Endevco ${ }^{\mathbb{}}$ Isotron 65HT, $\pm 50 \mathrm{~g}$, weight: $5 \mathrm{~g}$ ) fixed on a balsa wood board $(20 \mathrm{~mm} \times 10 \mathrm{~mm} \times 2 \mathrm{~mm}$ ) which was itself glued on subjects' skin on the medial face of the tibia halfway between medial maleolus and medial knee condyle [20]. In order to minimize differences in acceleration data between the skin and the bone [21], an accelerometer as light as possible was selected. Data were recorded at $2000 \mathrm{~Hz}$ (except for the kinematics recorded at $125 \mathrm{~Hz}$ ) and synchronized using Nexus ${ }^{\circledR}$ Software.

\subsection{Data analysis}

Using OpenSim software, a generic model [22] was scaled to match the subject's anthropometric measurements based on experimentally measured marker positions for static poses. In order to reduce the measurements errors due to marker movement on the subject's skin, an inverse kinematics algorithm was used to solve for the minimum of the difference between experimental and virtual markers [23]. The outputs of this inverse kinematics step consisted in joint angles through time. Joint flexion ranges of motion during stance phase were computed between angle at touchdown and maximal flexion angle during stance-phase.

Force and acceleration data were filtered (Butterworth, 2nd order, low pass, cut off frequency: $50 \mathrm{~Hz}$ ) before computation of the transient peak of the vGRF, the loading rate, and the tibial acceleration peak and rate. Loading and acceleration slopes were calculated between two end points describing $20 \%$ and $80 \%$ of the peaks amplitudes, as in Duquette et al. [24]. When no distinct impact transient was present on VGRF, the signal amplitude was measured using the average impact transient peak time as determined for each condition in trials with an impact transient. Strike index (SI) has been defined as the intersection point between the foot segment in sagittal plane and the perpendicular line from this segment to the center of pressure at touchdown [14,25]. This point was expressed in percentage of foot length.

Center of mass vertical displacement was estimated using OpenSim software with kinematic data and anthropometric characteristics of the scaled model. External net joint moments were computed using inverse dynamic procedure. External net joint moments were scaled to body mass. Knee and ankle stiffness were calculated by dividing net moment changes by angular changes between touchdown and maximal flexion angle [26] 
(Eq. (1)).

$\mathrm{ST}_{\text {Joint }}=\frac{\Delta M_{\text {Joint }}}{\Delta \alpha_{\text {Joint }}}$

with $\mathrm{ST}_{\text {Joint }}$, the stiffness of concerned joint $\left(\mathrm{kN} \mathrm{m} \mathrm{BM}^{-1} /^{\circ}\right) ; \Delta M_{\text {Joint }}$, the joint moment change from touchdown to maximal flexion angle $\left(\mathrm{kN} \mathrm{m} \mathrm{BM}^{-1}\right) ; \Delta \alpha_{\text {Joint }}$, the joint flexion angle change from touchdown to maximal flexion angle $\left({ }^{\circ}\right)$.

Global leg stiffness was computed using Eqs. (2) and (3) given by Farley et al. [27] where the leg is considered as a spring.

$\mathrm{ST}_{\text {Leg }}=\frac{F_{\max }}{\Delta L}$

$\Delta L=L_{0}-\sqrt{L_{0}^{2}-\left(\frac{v \times \mathrm{SPD}}{2}\right)^{2}}+\Delta z$

with $\mathrm{ST}_{\text {Leg }}$, the leg stiffness $\left(\mathrm{kN} \mathrm{m}^{-1}\right) ; F_{\max }$, the maximum value of the VGRF (kN); $\Delta L$, the compression of the spring from touchdown to maximal compression (m); $L_{0}$, the spring length at touchdown $(\mathrm{m}) ; v$, the speed in forward direction of the participant center of mass ( $\mathrm{m} \mathrm{s}^{-1}$ ); SPD, the stance-phase duration (s); $\Delta z$, the center of mass ( $\mathrm{CoM})$ vertical displacement from touchdown to maximum compression of the spring $(\mathrm{m})$.

\subsection{Statistical analysis}

Standard statistical methods were used in the calculation of means and standard deviation of the parameters studied for each participant and each condition. Repeated analysis of variance (Statistica ${ }^{\circledR}$, Statsoft) measures were used to test the influence of the footwear factor on the dependant variables (see Table 1 for a summary of the computed variables and their abbreviations). All significant effects $(p<0.05)$ were followed by Tukey post hoc tests.

\section{Results}

The two variables illustrating impact magnitude: vGRF and tibial acceleration showed no significant effect of footwear
Table 1

Description of the computed kinematics, ground reaction forces and tibial acceleration variables.

\begin{tabular}{|c|c|c|}
\hline Variable & Description & Unit \\
\hline SPD & Stance-phase duration & $\mathrm{s}$ \\
\hline SI & Strike index & $\%$ foot length \\
\hline ATD $_{\text {Foot }}$ & Sagittal foot/ground angle at touchdown & $\circ$ \\
\hline ATD $_{\text {Ankle }}$ & Ankle flexion angle at touchdown & $\circ$ \\
\hline ATD $_{\text {Knee }}$ & Knee flexion angle at touchdown & $\circ$ \\
\hline ATD $_{\text {Hip }}$ & Hip flexion angle at touchdown & $\circ$ \\
\hline $\mathrm{FRoM}_{\text {Ankle }}$ & Ankle flexion range of motion during stance phase & $\circ$ \\
\hline $\mathrm{FRoM}_{\text {Knee }}$ & Knee flexion range of motion during stance phase & $\circ$ \\
\hline $\mathrm{FRoM}_{\text {Hip }}$ & Hip flexion range of motion during stance phase & $\circ$ \\
\hline $\mathrm{M}_{\text {Ankle }}$ & Maximal ankle flexion moment during stance phase & $\mathrm{N} \mathrm{mBM}^{-1}$ \\
\hline$M_{\text {Knee }}$ & Maximal knee flexion moment during stance phase & $\mathrm{N} \mathrm{mBM}^{-1}$ \\
\hline $\mathrm{M}_{\mathrm{Hip}}$ & Maximal hip flexion moment during stance phase & $\mathrm{N} \mathrm{mBM}^{-1}$ \\
\hline $\mathrm{ST}_{\text {Ankle }}$ & Ankle stiffness & $\mathrm{kN} \mathrm{m} \mathrm{BM}^{-1} /^{\circ}$ \\
\hline $\mathrm{ST}_{\text {Knee }}$ & Knee stiffness & $\mathrm{kN} \mathrm{m} \mathrm{BM}^{-1} / \circ$ \\
\hline $\mathrm{ST}_{\text {Leg }}$ & Global leg stiffness & $\mathrm{kN} \mathrm{m}^{-1}$ \\
\hline PP & Transient peak of vertical ground reaction force & BW \\
\hline LR & Loading rate of vertical ground reaction force & $\mathrm{BW} \mathrm{s}^{-1}$ \\
\hline $\mathrm{AP}$ & Tibial acceleration peak & $\mathrm{g}$ \\
\hline AR & Tibial acceleration rate & $\mathrm{g} \mathrm{s}^{-1}$ \\
\hline
\end{tabular}

condition, whatever the parameter investigated (PP, LR, AP and AR) (Table 2).

There was a significant effect of the footwear factor on the SPD $\left(F_{5,70}=3.51, p=0.007\right)$. The post-hoc test indicated that BARE and $0 \mathrm{~mm}$ conditions showed lower SPD than $16 \mathrm{~mm}$ condition ( $251 \pm 21 \mathrm{~ms}$ and $252 \pm 33 \mathrm{~ms}$ versus $265 \pm 28 \mathrm{~ms}$, respectively) (Table 2).

At touchdown, no significant difference was observed across footwear conditions on the hip (Fig. 1A) and knee flexion angles (Fig. 1B). However, angles of the ankle (Fig. 1C) and foot in the sagittal plane were different between BARE and shod conditions regarding the joint flexion, foot/ground angle and the SI. There was an effect of footwear on ankle flexion angle at touchdown $\left(F_{5,70}=21.29, p<0.001\right)$ with BARE condition different from all others with the ankle joint in plantar-flexion for the BARE condition $\left(-1.5 \pm 8.2^{\circ}\right)$ and in dorsiflexion $\left(9.7 \pm 9.3^{\circ}\right)$ for all the shod conditions. Footwear conditions also affected foot/ground angle at touchdown $\left(F_{5,70}=23.03, p<0.001\right)$. Indeed all shoe conditions

Table 2

Mean values and standard deviations (SD) of all variables for each experimental condition.

\begin{tabular}{|c|c|c|c|c|c|c|c|c|c|c|c|c|}
\hline & \multicolumn{2}{|l|}{ BARE } & \multicolumn{2}{|l|}{$00 \mathrm{~mm}$} & \multicolumn{2}{|l|}{$02 \mathrm{~mm}$} & \multicolumn{2}{|l|}{$04 \mathrm{~mm}$} & \multicolumn{2}{|l|}{$08 \mathrm{~mm}$} & \multicolumn{2}{|l|}{$16 \mathrm{~mm}$} \\
\hline & Mean & SD & Mean & SD & Mean & SD & Mean & SD & Mean & SD & Mean & SD \\
\hline SPD & $0.251^{16 \mathrm{~mm}}$ & 0.021 & $0.252^{16 \mathrm{~mm}}$ & 0.033 & 0.257 & 0.030 & 0.257 & 0.028 & 0.263 & 0.020 & 0.265 & 0.028 \\
\hline SI & $57.3^{*}$ & 22.3 & $42.9^{\text {bare }}$ & 19.5 & $46.4^{\text {bare }}$ & 23.3 & $44.0^{\text {bare }}$ & 24.2 & $46.3^{\text {bare }}$ & 22.1 & 41.0 $0^{\text {bare }}$ & 23.7 \\
\hline ATD $_{\text {Foot }}$ & $0.8^{*}$ & 8.4 & $13.3^{\text {bare }}$ & 11.4 & $14.6^{\text {bare }}$ & 12.8 & $13.4^{\text {bare }}$ & 12.7 & $14.2^{\text {bare }}$ & 12.1 & $15.5^{\text {bare }}$ & 11.0 \\
\hline ATD $_{\text {Ankle }}$ & $-1.5^{*}$ & 8.2 & $9.8^{\text {bare }}$ & 9.1 & $9.5^{\text {bare }}$ & 10.6 & $9.4^{\text {bare }}$ & 9.5 & $9.2^{\text {bare }}$ & 10.1 & $10.8^{\text {bare }}$ & 8.0 \\
\hline ATD $_{\text {Knee }}$ & 20.1 & 4.3 & 20.4 & 4.7 & 19.3 & 3.9 & 19.7 & 6.5 & 20.3 & 8.4 & 19.9 & 7.1 \\
\hline $\mathrm{ATD}_{\text {Hip }}$ & 39.6 & 7.1 & 39.4 & 5.4 & 40.2 & 4.6 & 38.7 & 6.3 & 38.5 & 5.3 & 37.1 & 4.8 \\
\hline FRoM $_{\text {Ankle }}$ & $30.0^{*}$ & 8.6 & $22.7^{\text {bare }}$ & 8.5 & $22.5^{\text {bare }}$ & 10.4 & $22.9^{\text {bare }}$ & 9.5 & $22.4^{\text {bare }}$ & 10.0 & $22.9^{\text {bare }}$ & 9.6 \\
\hline FRoM $_{\text {Knee }}$ & 27.0 & 3.5 & 27.9 & 5.0 & $29.9^{\text {bare }}$ & 5.0 & $29.8^{\text {bare }}$ & 5.3 & $30.0^{\text {bare }}$ & 4.3 & $30.0^{\text {bare }}$ & 4.5 \\
\hline $\mathrm{FRoM}_{\text {Hip }}$ & 2.8 & 2.2 & 3.1 & 2.1 & 3.5 & 2.0 & 3.2 & 2.4 & 3.8 & 2.2 & 3.7 & 2.2 \\
\hline $\mathrm{M}_{\text {Ankle }}$ & 2.86 & 0.25 & 2.99 & 0.36 & 2.97 & 0.27 & 2.96 & 0.28 & 2.90 & 0.23 & 2.93 & 0.31 \\
\hline $\mathrm{M}_{\text {Knee }}$ & 2.59 & 0.41 & $2.78^{\text {bare }}$ & 0.46 & 2.74 & 0.51 & $2.76^{\text {bare }}$ & 0.46 & 2.73 & 0.53 & 2.76 & 0.46 \\
\hline $\mathrm{M}_{\text {Hip }}$ & 3.04 & 0.85 & 3.06 & 0.85 & 3.30 & 0.65 & 3.24 & 0.67 & 3.31 & 0.98 & 3.13 & 0.60 \\
\hline $\mathrm{ST}_{\text {Ankle }}$ & $102^{*}$ & 32 & $147^{\text {bare }}$ & 50 & $154^{\text {bare }}$ & 63 & $148^{\text {bare }}$ & 54 & $151^{\text {bare }}$ & 57 & $150^{\text {bare }}$ & 41 \\
\hline $\mathrm{ST}_{\text {Knee }}$ & 111 & 16 & 117 & 28 & 107 & 23 & 108 & 26 & 108 & 23 & 106 & 19 \\
\hline $\mathrm{ST}_{\text {Leg }}$ & 12.7 & 3.8 & 12.4 & 3.8 & 11.8 & 3.7 & 12.0 & 3.5 & $11.6^{\text {bare }}$ & 2.8 & $11.6^{\text {bare }}$ & 3.2 \\
\hline PP & 2.02 & 0.73 & 1.87 & 0.70 & 1.86 & 0.64 & 1.85 & 0.61 & 1.84 & 0.70 & 1.93 & 0.63 \\
\hline LR & 184 & 120 & 175 & 91 & 140 & 56 & 146 & 55 & 132 & 53 & 137 & 54 \\
\hline $\mathrm{AP}$ & 12.4 & 5.8 & 11.0 & 6.3 & 10.7 & 4.9 & 11.4 & 4.0 & 11.5 & 5.8 & 10.9 & 4.3 \\
\hline AR & 1270 & 808 & 1233 & 1086 & 1108 & 544 & 1104 & 495 & 1118 & 614 & 1069 & 580 \\
\hline
\end{tabular}

" Significant difference with all other conditions. "bare" in superscript: significant difference with BARE condition. 16 mm: significant difference with 16 mm condition. $p<0.05$. 

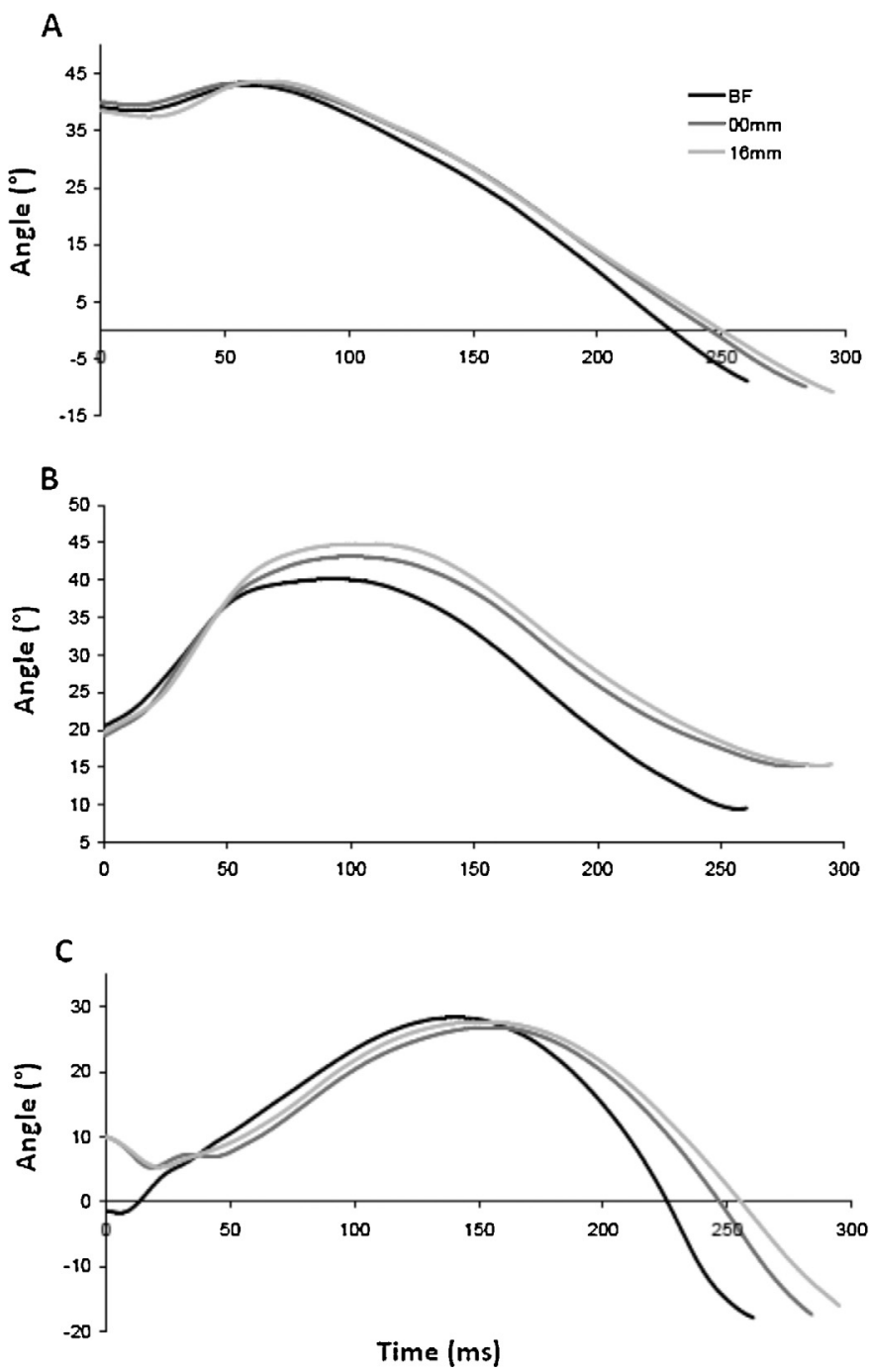

Fig. 1. Hip flexion (A), knee flexion (B) and ankle dorsiflexion (C) angles (in ${ }^{\circ}$ ) during stance phase duration (in $\mathrm{ms}$ ) for BARE condition (black line), $00 \mathrm{~mm}$ condition (light gray line) and $16 \mathrm{~mm}$ condition (dark gray line), during one typical trial. Positive values represent joint flexion.

showed higher foot/ground angle at impact $\left(14.2 \pm 11.7^{\circ}\right)$ than BARE $\left(0.8 \pm 8.4^{\circ}\right)$ (Table 2). SI was higher during BARE condition $\left(F_{5,70}=4.84, p=0.001\right)$ than during shod running $(57.3 \pm 22.3 \%$ vs. $44.1 \pm 22.1 \%$ ). However, all conditions exhibited SI located between $33 \%$ and $66 \%$ of the foot length (Fig. 2) that can be considered as midfoot strike [25].

During stance phase, our results did not show any difference on hip FRoM but there was a footwear effect on knee $\left(F_{5,70}=5.13\right.$, $p<0.001)$ and ankle flexion ranges of motion $\left(F_{5,70}=8.68\right.$, $p<0.001)$. Knee FRoM was lower in BARE $\left(27.0 \pm 3.5^{\circ}\right)$ condition than in $2 \mathrm{~mm}\left(29.9 \pm 5.0^{\circ}\right), 4 \mathrm{~mm}\left(29.9 \pm 5.3^{\circ}\right), 8 \mathrm{~mm}\left(30.0 \pm 4.3^{\circ}\right)$ and $16 \mathrm{~mm}\left(30.0 \pm 4.5^{\circ}\right)$ conditions. Ankle FRoM was higher during BARE condition $\left(30.0 \pm 8.6^{\circ}\right)$ compared to all the shod conditions $\left(22.7 \pm 9.4^{\circ}\right)$ (Table 2$)$.

Inverse dynamics outputs showed no difference between footwear conditions on maximal hip and ankle net joints moments (Fig. 3), but showed a footwear effect on maximal knee joint moment $\left(F_{5,70}=2.80, p=0.023\right)$. Maximal knee joint moments were lower for BARE condition $\left(2.59 \pm 0.51 \mathrm{~N} \mathrm{~m} \mathrm{BM}^{-1}\right)$ than for $0 \mathrm{~mm}\left(2.78 \pm 0.46 \mathrm{~N} \mathrm{~m} \mathrm{BM}^{-1}\right)$ and $4 \mathrm{~mm}\left(2.76 \pm 0.46 \mathrm{~N} \mathrm{~m} \mathrm{BM}^{-1}\right)$ conditions (Table 2).

Knee stiffness was not affected by footwear conditions but ankle stiffness was lower $\left(F_{5,70}=8.20, p<0.001\right)$ in BARE condition

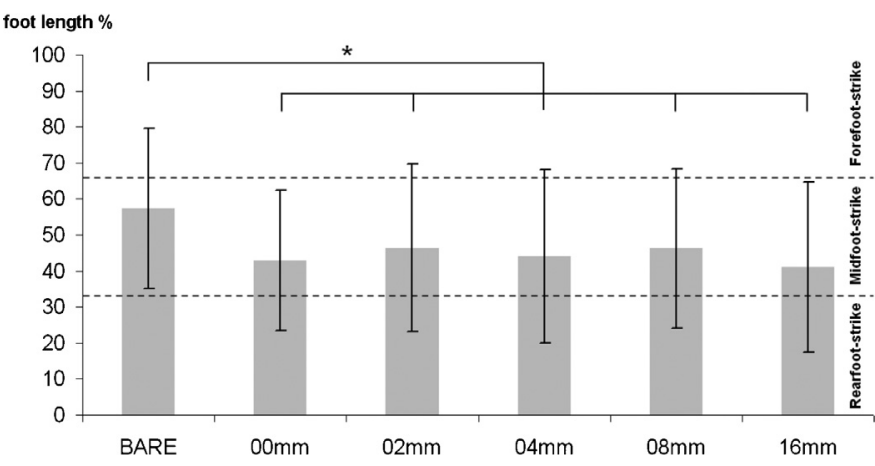

Fig. 2. Mean over all the participants $( \pm S D)$ SI parameter expressed in percentage of foot length. The three impact localisations: rearfoot (between $0 \%$ and $33 \%$ of foot length), midfoot (between $33 \%$ and $66 \%$ of foot length) and forefoot (between $66 \%$ and $100 \%$ of foot length) are indicated.
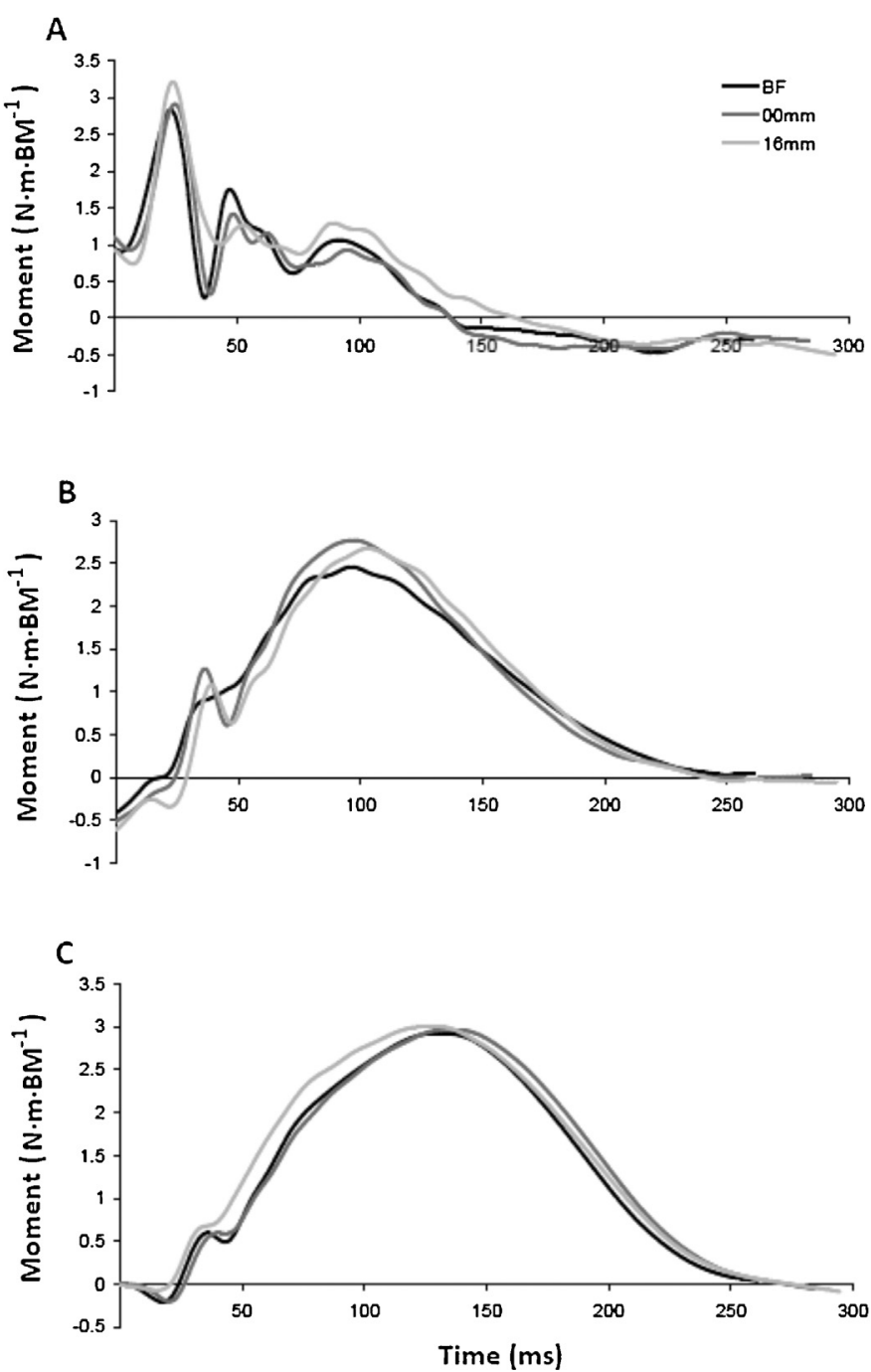

Fig. 3. Hip flexion moment (A), knee flexion moment (B) and ankle dorsiflexion moment (C) (in $\mathrm{N} \mathrm{m} \mathrm{BM}^{-1}$ ) during stance phase duration (in $\mathrm{ms}$ ) for BARE condition (black line), $00 \mathrm{~mm}$ condition (light gray line) and $16 \mathrm{~mm}$ condition (dark gray line), during one typical trial. Positive values represent external moments of joint flexion/ dorsiflexion.

$\left(102 \pm 32 \mathrm{kN} \mathrm{m} \mathrm{BM}^{-1} /{ }^{\circ}\right)$ than for all shoe conditions $(150 \pm$ $\left.52 \mathrm{kN} \mathrm{m} \mathrm{BM}^{-1} /{ }^{\circ}\right)$. Global leg stiffness was also affected by footwear condition $\left(F_{5,70}=3.20, p=0.012\right)$, and was higher for BARE condition $\left(12.7 \pm 3.8 \mathrm{kN} \mathrm{m}^{-1}\right)$ than for $08 \mathrm{~mm}\left(11.6 \pm 2.8 \mathrm{kN} \mathrm{m}^{-1}\right)$ and $16 \mathrm{~mm}$ $\left(11.6 \pm 3.2 \mathrm{kN} \mathrm{m}^{-1}\right)$ conditions (Table 2). 


\section{Discussion}

The aim of this study was to investigate the effects of midsole thickness on running patterns and impact forces. Fifteen subjects ran barefoot and with similar $0 \mathrm{~mm}$ heel to toe drop shoes only differing in the height of the midsole (from 0 to $16 \mathrm{~mm}$ of EVA).

Stance-phase duration was the only parameter that was directly influenced by the midsole thickness. Indeed, the results showed that an increase of $16 \mathrm{~mm}$ of midsole thickness induced a $5 \%$ increase of the stance-phase duration while the running speed was kept similar. It is interesting to note that our observations are in line with those from Morin et al. [28]. These authors showed that contact time is the most important parameter influencing leg stiffness. From their data, a 10\% increase in contact time leads to a $25 \%$ reduction in leg stiffness and our observations are similar to these findings as for $5 \%$ increase in contact time (between barefoot and $16 \mathrm{~mm}$ condition) a decrease of $10 \%$ in leg stiffness was observed. Two factors can explain these differences. First, the presence of a thick midsole may slow the progress of the foot segment towards the ground following landing but, in turn, the midsole needs some time to be deformed, thus increasing the stance phase duration. Second, it has been demonstrated that the contact time could depend on the global leg stiffness [29]. In this case, the lower limb is represented as a spring where the global leg stiffness is the stiffness of the spring. When the stiffness of the spring increases, the vertical displacement of the center of mass decreases and the duration between touchdown and mid-stance decreases [27]. In the present study, the two least stiff shoe conditions, $\quad 08 \mathrm{~mm} \quad\left(11.6 \pm 2.8 \mathrm{kN} \mathrm{m}^{-1}\right) \quad$ and $\quad 16 \mathrm{~mm}$ $\left(11.6 \pm 3.2 \mathrm{kN} \mathrm{m}^{-1}\right)$, induced lower global leg stiffness than BARE condition $\left(12.7 \pm 3.8 \mathrm{kN} \mathrm{m}^{-1}\right)$. All the experimental shoes had the same midsole material but a different thickness and thus a different stiffness. Shoe stiffness might explain the resulting differences on leg stiffness. Indeed, like Divert et al. [12], our results showed an increase of SPD when shoe thickness increased.

It seems important to highlight that all the observed impacts were located on the midfoot part $(33 \%<\mathrm{SI}<66 \%)$ whatever the condition. Indeed, previous studies have shown rearfoot strikes during shod running ( $\mathrm{SI}<33 \%$ ) [14,30]. Given the results from Hamill and Paquette, our results showing midfoot strike is an important one. Based on these results, it can be supposed that repetitive midfoot strikes for runners who are usually impacting the ground with the rear part of their foot would lead to increased risk of injury. Indeed previous studies have shown that running in minimalist shoe (which causes midfoot strike rather than rearfoot strike for habitually shod runners) can lead to metatarsal stress injuries [31,32].

Contrary to what was hypothesised, different thickness conditions did not induce any difference on the running pattern, thus revealing that an increase of midsole thickness from 0 to $16 \mathrm{~mm}$ had no effect on the foot strike pattern, neither for the kinematics (i.e., joint angles through time), nor the force or acceleration variables. Keeping in mind that uppers, outsoles, and midsole material were identical between shod conditions, these results suggest that for habitually shod runners mechanical properties of the whole sole (different thicknesses, and thus different stiffnesses) did not play a key role in altering running pattern from touch-down to midstance.

While few differences were noted in between the shod conditions, many differences were observed between barefoot and shod conditions. The ankle joint was plantar flexed at touchdown during barefoot unlike shod running and the ankle flexion range of motion after touchdown was higher during barefoot than during shod running. The difference in ankle flexion range of motion between BARE and shod conditions ( $30.0 \pm 8.6^{\circ}$ in barefoot vs. $22.7 \pm 9.7^{\circ}$ in shod conditions) which can be interpreted as a strategy of impact attenuation was sufficient to explain lower ankle stiffness during barefoot condition despite the absence of any difference on ankle net joint moments across conditions. Results on reduction of the ankle stiffness during barefoot condition are in agreement with previous studies $[5,16]$. Concerning the knee joint, results showed higher flexion range of motion after touchdown for four shod conditions $(2 \mathrm{~mm}, 4 \mathrm{~mm}, 8 \mathrm{~mm}, 16 \mathrm{~mm}$, mean $\left.=29.9 \pm 4.7^{\circ}\right)$ compared to the barefoot condition $\left(27 \pm 3.5^{\circ}\right)$. Thus, in order to limit the propagation of the impact energy, the participant adaptation leads to an increased knee flexion during shod running. A meaningful difference in the kinematic organization of movement between barefoot and shod running was thus noted. Indeed, during shod running, ankle joint is in dorsiflexion at touchdown, so this joint could not act as a damper. It can be hypothesized that, if the ankle joint is in plantar flexion at touch down, eccentric contraction of gastrocnemii and soleus muscles may occur during first instants of foot-ground contact, thus making the ankle joint acting as a damper to reduce impact amplitude and potential traumatisms linked to the vertical ground reaction force (e.g., tibial stress fracture [8]). However this touch down configuration induces high strains on the Achilles tendon. Indeed, Gruber [33] showed that soleus peak force production was $18 \%$ greater during forefoot strike running compared to rearfoot strike running. In nonhabitual barefoot runners, this unusual greater force production may increase injury risks over the calf muscle tendon system. These adaptations can explain the absence of difference concerning vGRF and tibial acceleration through footwear conditions.

The main hypothesis of the present study was that midsole thickness has an effect on impact magnitude and more specifically on vGRF and tibial acceleration. Instead, results showed that, keeping zero heel to toe drop, midsole thickness did not affect foot strike pattern but that foot strike patterns were different between barefoot and shod running. A previous study also investigated the effect of several midsole thickness compared to barefoot and showed higher loading rates and peaks on vGRF with all shoe conditions compared to barefoot running [14].

In order to compare barefoot and shod conditions, the midsoles of the shoes of the present study presented no height difference in between the rear and the front part ( $0 \mathrm{~mm}$ heel to toe drop) because barefoot is, by essence, a $0 \mathrm{~mm}$ heel to toe drop condition. For habitually shod runners, it has been stated that a height difference between the rearfoot and the forefoot part of the shoe would cause heel impact during running [5]. Contrary to our study, Hamill et al. [14] used several shoes of different thickness but with $4 \mathrm{~mm}$ heel to toe drop, making them different from barefoot on at least two parameters (thickness and heel to toe drop), and thus making the comparison with barefoot less obvious. As a result, the strike index of all our experimental conditions were between 33\% and $66 \%$ (midfoot strike), while strike index during shod conditions of Hamill et al. [14] were below 33\% (rearfoot strike). In addition, differences in ankle flexion angle between shod conditions at impact were lower in the present study $\left(18.3^{\circ}\right.$ for Hamill et al. [14] vs. $11.2^{\circ}$ in our study). The heel impacts observed by Hamill et al. [14] could explain higher LR and PP observed on vGRF. We supposed that running shoes (with heel to toe drop higher than $0 \mathrm{~mm}$ ), would provide higher impact features than the $0 \mathrm{~mm}$ heel to toe drop shoes used in the present study. However, this hypothesis needs to be tested with a specific protocol design. Concerning the absence of effect on vGRF and tibial acceleration across midsole thickness, our results together with those of Hamill et al. [14] may suggest that these variables are more affected by the heel to toe drop than by the thickness.

Our results, as other previous studies [14,16], showed differences between barefoot running and shod running (all shoe conditions included) concerning foot strike pattern kinematics. Interestingly, this study showed that the presence of a very thin 
shoe upper and sole (no midsole, $3 \mathrm{~mm}$ of rubber outsole only) was sufficient to induce significant alteration on foot strike pattern, compared to barefoot. It could be suspected that the presence of a material covering the foot surface played an important role in the modification of these patterns. Indeed it has been suggested that mechanical constraints applied to the foot movements and deformations by the sole and the upper may potentially affect the foot strike pattern [34]. The presence of sole and upper around the foot may restrict foot deformation and/or proprioception [35] and in consequence modify the foot strike pattern. This would explain the differences between barefoot and shod running, especially for the $00 \mathrm{~mm}$ condition.

One of the main limits of this study lies in the task performed by the subjects. Indeed participants had to realize a difficult task in which they were asked to run at a fixed speed while impacting a force plate with their right foot. A more ecological task would potentially reveal stronger results (in term of conditions differentiations). Moreover, the present study only observed acute effects, thus future studies should observe the long-term effects of changing shoes, for example during a training plan of several months.

To conclude, midsole thickness variations only affect stance phase duration. In contrast, the presence of footwear (even with a very thin upper and sole) was sufficient to strongly influence the running pattern.

\section{Acknowledgment}

The authors would like to thank Dr. Lise Sissler for her helpful comments on this manuscript.

\section{Conflict of interest}

All authors disclose that there was no conflict of interest regarding this study.

\section{References}

[1] Taunton JE, Ryan MB, Clement DB, McKenzie DC, Lloyd-Smith DR, Zumbo BD. A prospective study of running injuries: the Vancouver Sun Run "In Training" clinics. Br J Sports Med 2003;37:239-44.

[2] Taunton JE, Ryan MB, Clement DB, McKenzie DC, Lloyd-Smith DR, Zumbo BD. A retrospective case-control analysis of 2002 running injuries. Br J Sports Med 2002;36:95-101.

[3] Theisen D, Malisoux L, Genin J, Delattre N, Seil R, Urhausen A. Influence of midsole hardness of standard cushioned shoes on running-related injury risk. Br J Sports Med 2013 [Epub ahead of print].

[4] Shorten MR. Running shoe design: protection and performance. In: Pedoe DT, editor. Marathon medicine. London: Royal Society of Medicine; 2000. p. 15969.

[5] Lieberman DE, Venkadesan M, Werbel WA, Daoud AI, D’Andrea S, Davis IS, et al. Foot strike patterns and collision forces in habitually barefoot versus shod runners. Nature 2010;463:531-5.

[6] Kerr BA, Beauchamp L, Fisher Y, Neil R. Footstrike patterns in distance running. In: Nigg BM, Kerr BA, editors. Biomechanical aspects of sport shoes and playing surfaces. Calgary, Canada: University Printing; 1983. p. 135-42.
[7] Larson P, Higgins E, Kaminski J, Decker T, Preble J, Lyons D, et al. Foot strike patterns of recreational and sub-elite runners in a long-distance road race. J Sports Sci 2011;29:1665-73.

[8] Milner CE, Ferber R, Pollard CD, Hamill J, Davis IS. Biomechanical factors associated with tibial stress fracture in female runners. Med Sci Sports Exerc 2006;38:323-8

[9] Daoud AI, Geissler GJ, Wang F, Saretsky J, Daoud YA, Lieberman DE. Foot strike and injury rates in endurance runners: a retrospective study. Med Sci Sports Exerc 2012;44:1325-34.

[10] Divert C, Mornieux G, Baur F, Mayer F, Belli A. Mechanical comparison of barefoot and shod running. Int J Sports Med 2005;26:593-8.

[11] De Wit B, De Clercq D, Aerts P. Biomechanical analysis of the stance phase during barefoot and shod running. J Biomech 2000;33:269-78.

[12] Divert C, Baur H, Mornieux G, Mayer F, Belli A. Stiffness adaptations in shod running. J Appl Biomech 2005;21:311-21.

[13] Fukano M, Nagano Y, Ida H, Fukubayashi T. Change in tibial rotation of barefoot versus shod running. Footwear Sci 2009;1:19-23.

[14] Hamill J, Russel EM, Gruber AH, Miller R. Impact characteristics in shod and barefoot running. Footwear Sci 2011;3:33-40.

[15] Kerrigan DC, Franz JR, Keenan MD, Dicharry J, Della Croce U, Wilder RP. The effect of running shoes on lower extremity joint torques. PM R 2009;1:105863.

[16] Bishop M, Fiolkowski P, Conrad B, Brunt D, Horodyski MB. Athletic footwear leg stiffness, and running kinematics. J Athl Train 2006;41:387-92.

[17] Robbins SE, Gouw GJ. Athletic footwear: unsafe due to perceptual illusions. Med Sci Sports Exerc 1991;23:217-24.

[18] Kadaba MP, Ramakrishnan HK, Wootten ME. Measurement of lower extremity kinematics during level walking. J Orthop Res 1990;8:383-92.

[19] Hamner SR, Seth A, Delp SL. Muscle contributions to propulsion and support during running. J Biomech 2010;43:2709-16.

[20] Lafortune MA, Hennig EM, Lake MJ. Dominant role of interface over knee angle for cushioning impact loading and regulating initial leg stiffness. J Biomech 1996;29:1523-9.

[21] Ziegert JC, Lewis JL. The effect of soft tissue on measurements of vibrational bone motion by skin-mounted accelerometers. J Biomech Eng 1979;101:21820.

[22] Anderson FC, Pandy MG. A dynamic optimization solution for vertical jumping in three dimensions. Comput Methods Biomech Biomed Eng 1999;2:201-31.

[23] Delp SL, Anderson FC, Arnold AS, Loan P, Habib A, Guendelman E, et al. OpenSim: open-source software to create and analyze dynamic simulations of movement. IEEE Trans Biomed Eng 2007;54:1940-50.

[24] Duquette AM, Andrews DM. Comparing methods of quantifying tibial acceleration slope. J Appl Biomech 2010;26:229-33.

[25] Cavanagh PR, Lafortune MA. Ground reaction forces in distance running. ] Biomech 1980;13:397-406.

[26] Stefanyshyn DJ, Nigg BM. Dynamic angular stiffness of the ankle joint during running and sprinting. J Appl Biomech 1998;14:292-9.

[27] Farley CT, Gonzalez O. Leg stiffness and stride frequency in human running. J Biomech 1996;29:181-6.

[28] Morin JB, Dalleau G, Kyröläinen H, Jeannin T, Belli A. A simple method for measuring stiffness during running. J Appl Biomech 2005;21:167-80.

[29] Morin JB, Samozino P, Zameziati K, Belli A. Effects of altered stride frequency and contact time on leg-spring behavior in human running. J Biomech 2007; 40:3341-8.

[30] Paquette MR, Zhang S, Baumgartner DL. Acute effects of barefoot, minimal shoes and running shoes on lower limb mechanics in rear and forefoot strike runners. Footwear Sci 2013;5:9-18.

[31] Ridge ST, Johnson AW, Mitchell UH, Hunter I, Robinson E, Rich BS, et al. Foot bone marrow edema after a 10-wk transition to minimalist running shoes. Med Sci Sports Exerc 2013;45:1363-8.

[32] Giuliani J, Masini B, Alitz C, Owens BD. Barefoot-simulating footwear associated with metatarsal stress injury in 2 runners. Orthopedics 2011;34:e320-3.

[33] Gruber AH. Mechanics and energetics of footfall patterns in running.[Ph.D. thesis] Amherst: University of Massachusetts; 2012.

[34] Morio C, Gueguen N, Baly L, Berton E, Barla C. Relationship between biomechanical variables and sole viscoelasticity with fresh and fatigued running shoes. Footwear Sci 2009;1:111-3.

[35] Squadrone R, Galozzi C. Effect of a five-toed minimal protection shoe on static and dynamic ankle position sense. J Sports Med Phys Fitness 2011;51:401-8. 